Document downloaded from:

http://hdl.handle.net/10251/105477

This paper must be cited as:

García-Ivars, J.; Iborra Clar, MI.; Massella, M.; Carbonell Alcaina, C.; Alcaina-Miranda, MI. (2017). Removal of pharmaceutically active compounds using low-pressure membrane processes. Desalination and Water Treatment. 69:252-260. doi:10.5004/dwt.2017.0449

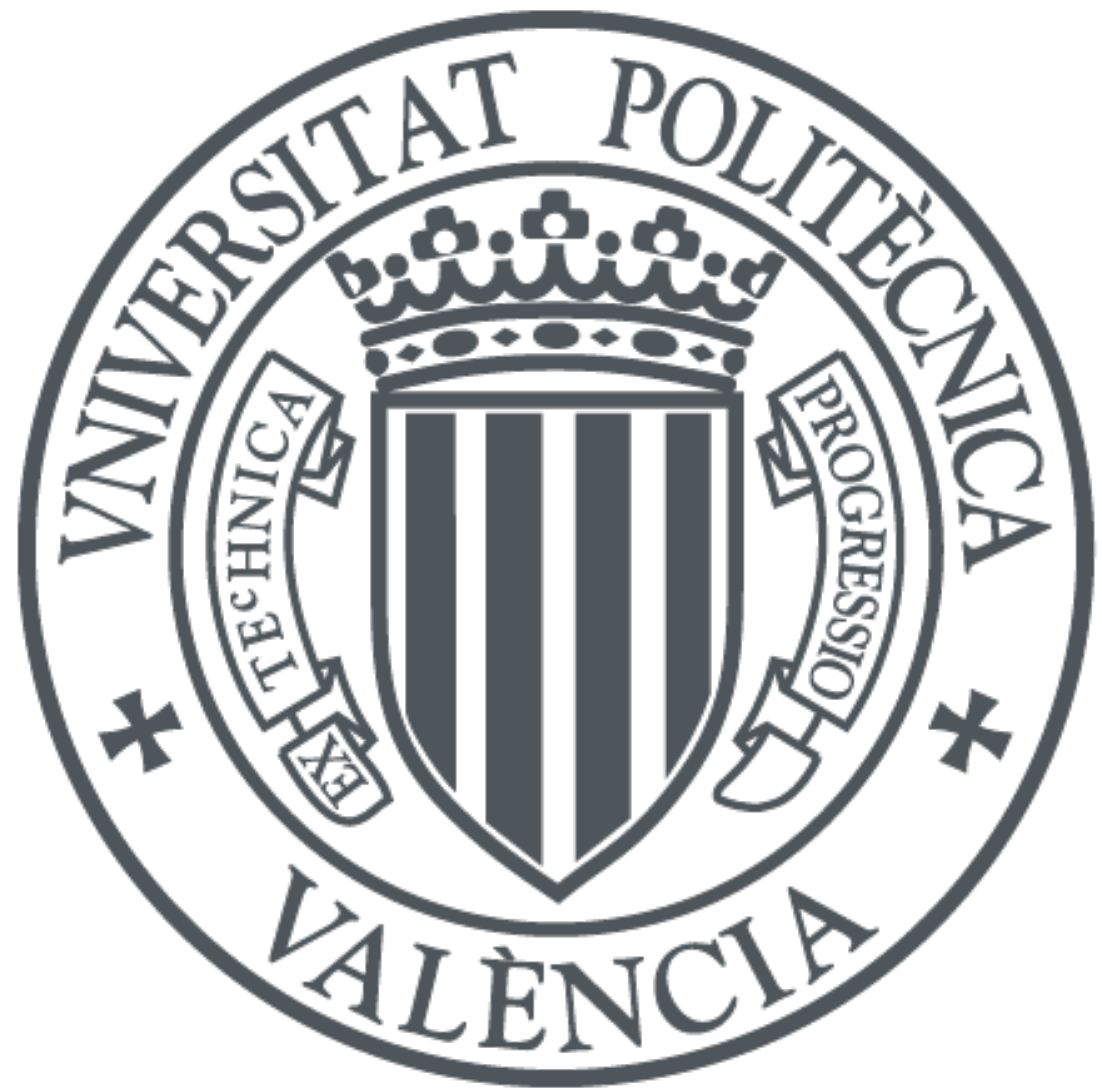

The final publication is available at

http://doi.org/10.5004/dwt.2017.0449

Copyright Taylor \& Francis

Additional Information 


\title{
Removal of pharmaceutically active compounds using low-pressure membrane processes
}

Jorge Garcia-Ivars*a, Maria-Isabel Iborra-Clar ${ }^{\mathrm{a}, \mathrm{b}}$, Manuele Massella ${ }^{\mathrm{c}}$, Carlos CarbonellAlcaina $^{\mathrm{a}}$, Maria-Isabel Alcaina-Miranda ${ }^{\mathrm{a}, \mathrm{b}}$

${ }^{a}$ Research Institute for Industrial, Radiophysical and Environmental Safety (ISIRYM), Universitat Politècnica de València, C/Camino de Vera s/n, 46022 Valencia, Spain

bDepartment of Chemical and Nuclear Engineering, Universitat Politècnica de València, C/Camino de Vera s/n, 46022 Valencia, Spain

'Dipartamento di Ingegneria Civile, Edile e Ambientale, Università Sapienza di Roma, Via Eudossiana 18, 00184 Rome, Italy

Tel. +34 963879633

Fax. +34 963877639

Emails: Dr. Jorge Garcia-Ivars (E-mail: jorgariv@posgrado.upv.es), Prof. Maria-Isabel Iborra-Clar (․miborra@iqn.upv.es), Manuele Massella (manuele_massella@hotmail.it), Carlos Carbonell-Alcaina (carcaral@posgrado.upv.es), and Prof. Maria-Isabel Alcaina-Miranda (malcaina@iqn.upv.es).

\begin{abstract}
The increasing demand on water resources throughout the world has motivated researchers to seek new ways to obtain quality water increasing their interest in water reclamation. However, the presence of harmful organic chemicals such as pharmaceutically active compounds (PhACs) is a serious environmental concern. The objective of this study was to investigate the influence of the $\mathrm{pH}$ on the rejection of seven target PhACs (acetaminophen, caffeine, erythromycin, ibuprofen, naproxen, sulfamethoxazole, and trimethoprim) by different low-pressure membranes within the
\end{abstract}


fine ultrafiltration (UF) and loose nanofiltration (NF) range. For this purpose, three ceramic membranes and a polyamide membrane were used for UF and NF experiments, respectively. Experimental results indicated that PhACs with negative charge were effectively rejected at basic conditions ( $<75 \%$ for UF, $<90 \%$ for NF), improving both their hydrophilicity and solubility with increasing $\mathrm{pH}$. Furthermore, high soluble PhACs with high pKa values showed low rejection values ( $15 \%$ for UF, $30 \%$ for NF) and a $\mathrm{pH}$-independent behaviour during low-pressure filtration experiments. Therefore, the use of low-pressure membranes could be considered as an appropriate and sustainable supplemental technique to remove PhACs in a wastewater treatment plant.

KEYWORDS Low-pressure membrane filtration systems; emerging contaminants; rejection efficiency; pharmaceutically active compounds; $\mathrm{pH}$; fouling.

\section{INTRODUCTION}

Water is a complex resource that occurs in a dynamic cycle with different temporal and spatial variations in quality and availability. Such variations can completely rate its value to people and ecosystems [1]. Nowadays, the demand of high-quality water is constantly increasing throughout the world due to the continuous and rapid growth of the human population, fast industrialisation, urbanisation and economy and the limited availability of water resources. For these reasons, water reclamation has received more and more attention as a sustainable water resource to suit the needs of society and the planet [2].

However, the growing presence of harmful organic chemicals (including pharmaceuticals, hormones, personal care products, pesticides, disinfection by-products, 
specific chemicals, and products of oil use and combustion) in water has become one of the most serious environmental concerns. These emerging contaminants are associated with potential human, animal and ecological problems and they are mainly entering the environment through their release as free without further treatments or conjugate metabolites or their excretion from the human or animal body [3,4]. Among them, active pharmaceutical ingredients (APIs) or pharmaceutically active compounds (PhACs) are a broad and diverse group of organic substances used for preventing and treating diseases in humans and animals [5]. Although PhACs are detectable in water at very low concentrations (in the range of $n g / L$ to $\mu \mathrm{g} / \mathrm{L}$ ), their presence and their consequences in the environment have not been sufficiently studied. Many researchers from a wide variety of backgrounds and countries have focused their efforts on removing PhACs from different wastewaters, but limited investigations have proved to be efficient in the removal of such compounds from contaminated waters. Activated carbon (as granular activated carbon or as powdered activated carbon) has been used for adsorption from wastewater effluent, obtaining high sorption efficiencies for PhACs and hydrophobic natural organic matter from wastewater effluent. However, their removal is simply a transfer from one phase to another one and the PhACs are not degraded in the process [6,7]. To overcome this problem, membrane technology has captured the attention of many researchers in different fields over the past few decades and it can play a crucial role in reclaiming treated industrial and domestic waters which contained PhACs in their composition. Numerous studies demonstrated that the application of nanofiltration (NF) and reverse osmosis (RO) provides high removal efficiencies of PhACs $[6,8,9]$. Low-pressure membrane filtration has been successfully applied in the removal of suspended solids natural organic matter (NOM), microorganisms and 
inorganic compounds from wastewater, but these membranes presented low removal efficiencies of PhACs when passing through the membrane system [6].

In this regard, there are a few studies about the application of low-pressure membranes in the removal of PhACs, especially its improvement using ceramic ultrafiltration by studying their interactions among each other at different $\mathrm{pH}$ conditions and with membranes of different molecular weight cut-offs (MWCOs). The objective of this study was to evaluate the performance of different ceramic low-pressure membranes (with a nominal MWCO of 1, 5 and $8 \mathrm{kDa}$, respectively) in removing seven targeted PhACs with diverse physicochemical characteristics at different $\mathrm{pH}$ conditions $(\mathrm{pH} 4,7$ and 10 for UF experiments and $\mathrm{pH}$ 6, 7, and 8 for NF experiments). Membrane fouling and rejection experiments were conducted using a crossflow membrane filtration test unit. High-Performance Liquid Chromatography (HPLC) analyses were used to calculate the concentration in feed, permeate and rejection streams and thus, the retention values for each PhACs.

\section{EXPERIMENTAL}

\section{Chemicals and Materials}

Seven different PhACs were selected for this study due to their persistence and occurrence in effluents from wastewater treatment plants and surface waters at the Spanish Mediterranean area of Valencia [10,11]. Reagent grade Ibuprofen (IBU), Acetaminophen (ACE), Sulfamethoxazole (SUL), Caffeine (CAF), Naproxen (NAP), Trimethoprim (TMT), and Erythromycin (ERY) were purchased from Sigma-Aldrich (Germany). The physicochemical properties of the target PhACs are shown in Table 1. 
make them interesting for the comparison and examination of their removal and their ability as foulants on/in low-pressure membranes (see Table 1). Unlike other organic and inorganic compounds, physicochemical properties of PhACs are strongly dependent on the $\mathrm{pH}$ conditions, which significantly affect both their fouling and retention behaviours [12]. This dependence is related to their value of dissociation constant $(p K a)$ which determines its ionic state. At higher $p H$ values than the characteristic pKa value of the solute, this will be negatively charged; otherwise this compound will be neutral or positively charged or a mixture of both [13]. The pH of feed solutions was adjusted using $0.1 \mathrm{M} \mathrm{HCl} / \mathrm{NaOH}$ solutions before starting membrane filtration. Both chemicals $(\mathrm{HCl}$ and $\mathrm{NaOH})$ were obtained of reagent grade from Panreac (Spain). Deionised water was used throughout this study.

Table 1. Physicochemical properties of the target PhACs studied.

\begin{tabular}{|c|c|c|c|c|c|c|c|c|c|}
\hline $\begin{array}{c}\text { Pharmaceutical } \\
\text { active } \\
\text { compound }\end{array}$ & CAS no. & Formula & $\begin{array}{c}\text { Molecular } \\
\text { weight } \\
\text { (g/mol) }^{\mathbf{a}}\end{array}$ & $\begin{array}{c}\text { Water } \\
\text { solubility } \\
\text { (mg/L) }\end{array}$ & $\begin{array}{c}\log P \\
(p H=7)^{a}\end{array}$ & $\begin{array}{l}\text { Log } \\
\text { Kow }^{b}\end{array}$ & $\mathbf{p K}_{\mathbf{a}}^{\mathbf{b}}$ & $\begin{array}{l}\text { Molecular } \\
\text { length } \\
(\mathrm{nm})\end{array}$ & $\begin{array}{l}\text { Charge } \\
(\mathrm{pH}=7)\end{array}$ \\
\hline Acetaminophen & $103-90-2$ & $\mathrm{C}_{8} \mathrm{H}_{9} \mathrm{NO}_{2}$ & 151.16 & 14,000 & 0.89 & $\begin{array}{c}0.46- \\
0.89\end{array}$ & $9.4 / 9.86$ & 1.14 & 0 \\
\hline Caffeine & 58-08-2 & $\mathrm{C}_{8} \mathrm{H}_{10} \mathrm{~N}_{4} \mathrm{O}_{2}$ & 194.19 & 22,000 & -0.80 & -0.07 & $10.4 / 14.0$ & 0.98 & 0 \\
\hline Erythromycin & $\begin{array}{c}23893- \\
13-2\end{array}$ & $\mathrm{C}_{37} \mathrm{H}_{67} \mathrm{NO}_{13}$ & 733.93 & 1.4 & 1.91 & 3.06 & 8.9 & 1.59 & 0 \\
\hline Ibuprofen & $\begin{array}{c}15687- \\
27-1\end{array}$ & $\mathrm{C}_{13} \mathrm{H}_{18} \mathrm{O}_{2}$ & 206.29 & $10-49$ & 3.14 & $\begin{array}{c}3.50- \\
3.97\end{array}$ & $4.4 / 4.91$ & 1.39 & -1 \\
\hline Naproxen & $\begin{array}{c}22204- \\
53-1\end{array}$ & $\mathrm{C}_{14} \mathrm{H}_{14} \mathrm{O}_{3}$ & 230.26 & $16-25$ & 2.86 & $\begin{array}{c}2.88- \\
3.18\end{array}$ & $4.15 / 4.5$ & 1.37 & -1 \\
\hline Sulfamethoxazole & $723-46-6$ & $\mathrm{C}_{10} \mathrm{H}_{11} \mathrm{~N}_{3} \mathrm{O}_{3} \mathrm{~S}$ & 253.28 & 600 & 0.86 & $\begin{array}{l}0.5- \\
0.89\end{array}$ & $\begin{array}{l}1.4 / 1.7- \\
5.5 / 5.7\end{array}$ & 1.33 & -1 \\
\hline Trimethoprim & $738-70-5$ & $\mathrm{C}_{14} \mathrm{H}_{18} \mathrm{~N}_{4} \mathrm{O}_{3}$ & 290.32 & 400 & 1.43 & $\begin{array}{c}0.59- \\
0.91\end{array}$ & 6.6/7.12 & 1.42 & +1 \\
\hline
\end{tabular}

a)Chem3D Ultra 8.0.

b)SciFinder Scholar, data calculated at $20^{\circ} \mathrm{C}$ and 760 torr using Advanced Chemistry Development (ACD/Labs) Software V11.02 (@1994-2016 ACD/Labs). 
Three different multichannel ceramic ultrafiltration (UF) membranes (INSIDE CéRAM $^{\mathrm{TM}}$, TAMI Industries, France) with a nominal MWCO of 1,000, 3,000 and 8,000 Da and a polymeric spiral wound NF membrane (TFC-SR2, KOCH Membrane Systems, USA) of 300-400 Da were used in order to represent a wide range of nominal MWCO and to compare their effectiveness in the removal of PhACs. Multichannel TiO2 membranes had a length of $25 \mathrm{~cm}$ with an external diameter of $1 \mathrm{~cm}$. The effective filtration area was $0.0132 \mathrm{~m}^{2}$ for ceramic UF membranes and $2.5 \mathrm{~m}^{2}$ for NF membrane. Their main properties and operational conditions are summarised in Table 2.

Table 2. Properties and relevant information of the selected membranes.

\begin{tabular}{ccccc}
\hline Membrane & UF8 & UF5 & UF1 & TFC-SR2 \\
\hline Manufacturer & $\begin{array}{c}\text { TAMI } \\
\text { Industries }\end{array}$ & $\begin{array}{c}\text { TAMI } \\
\text { Industries }\end{array}$ & $\begin{array}{c}\text { TAMI } \\
\text { Industries }\end{array}$ & $\begin{array}{c}\text { KOCH } \\
\text { Membrane } \\
\text { Systems }\end{array}$ \\
MWCO (Da) & 8,000 & 5,000 & 1,000 & $300-400$ \\
Active layer & & $\mathrm{TiO}_{2}$ & & Polyamide \\
Isoelectric electric & & $\sim 5.9-6.3$ & & $\sim 2-4$ \\
Water contact angle $\left({ }^{\circ}\right)^{b}$ & & $40 \pm 2.0$ & & $60.4 \pm 4.0$ \\
Water permeability $\left(\mathrm{L} / \mathrm{m}^{2} \cdot \mathrm{h} \cdot \mathrm{bar}^{\mathrm{c}}\right.$ & $60.7 \pm 3.0$ & $41.4 \pm 3.4$ & $36.2 \pm 2.1$ & $17.3 \pm 1.8$ \\
\hline
\end{tabular}

${ }^{a}$ References sources: [14] for fine UF membranes, and [15] for the loose NF membrane.

${ }^{b}$ References sources: [16,17] for fine UF membranes, and [15] for the loose NF membrane.

${ }^{c}$ Water permeability was determined using deionised water at different transmembrane pressures $(\Delta \mathrm{P})$ ranging from 0.5 to 3 bar at a constant flow rate of $300 \pm 10 \mathrm{~L} / \mathrm{h}$ for UF membranes, and $\Delta \mathrm{P}$ from 2 to 10 bar at a constant flow rate of $500 \pm 20 \mathrm{~L} / \mathrm{h}$ for the NF membrane.

\section{Low-pressure filtration experiments}

The experimental cross-flow filtration setup is schematically shown in Figure 1. This plant was equipped with a temperature-controlled feed tank with $25 \mathrm{~L}$ in volume, a filter to protect the pump of undesired pollution, a variable speed volumetric pump to adjust and maintain the feed flow (measured by a flow meter), and two manometers (P1 and P2) placed at the inlet and outlet of the cross-flow membrane module in order to regulate the transmembrane pressure. Finally, a scale with an accuracy of $\pm 0.001 \mathrm{~g}$ 
was employed to gravimetrically measure the permeate flux. Both membrane filtration processes (UF and NF) operated in a total recirculation mode. All experiments were carried out at a constant temperature of $25 \pm 2{ }^{\circ} \mathrm{C}$. Firstly, membranes were compacted using deionised water for at least $30 \mathrm{~min}, 3 \mathrm{bar}$, and $300 \mathrm{~L} / \mathrm{h}$ for ceramic UF membranes, whereas the operating parameters for compacting the polymeric NF membrane were $45-50 \mathrm{~min}, 10 \mathrm{bar}$, and $500 \mathrm{~L} / \mathrm{h}$. The water flux was generally stable after the selected compaction time, when differences between values of permeate flux during the filtration time were lower than $2 \%$ [18].

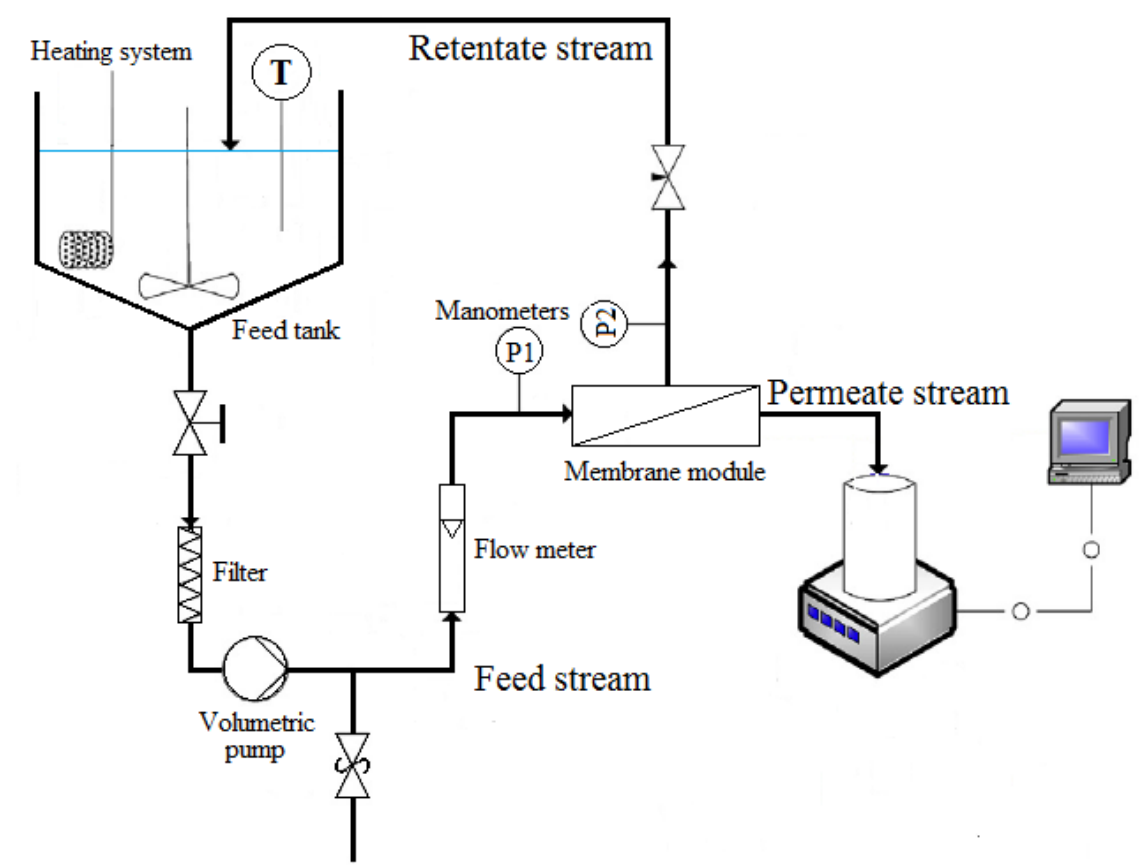

Figure 1. Schematic diagram of the cross-flow filtration set-up used for both UF and NF processes.

After the compaction procedure, UF experiments were carried out at a constant flow rate of $300 \pm 10 \mathrm{~L} / \mathrm{h}$ and 2 bar with model solutions for $3 \mathrm{~h}$, which were prepared at 500 $\mu \mathrm{g} / \mathrm{L}$ of each PhAC, separately. For NF experiments, the operating conditions were 500 $\pm 20 \mathrm{~L} / \mathrm{h}$ and 5 bar for $4 \mathrm{~h}$ using model solutions with a concentration of $1000 \mathrm{ng} / \mathrm{L}$ of IBU, ACE, and SUL, and $300 \mathrm{ng} / \mathrm{L}$ for the rest of PhACs. In order to evaluate the effect of $\mathrm{pH}$ on the removal efficiencies, acidic $(\mathrm{pH} 4)$, neutral $(\mathrm{pH} 7)$, and basic $(\mathrm{pH} 10)$ 
conditions were studied for UF experiments, and $\mathrm{pH}$ values between 6 and 8 were tested for NF experiments. For both filtration experiments, permeate flux $\left(J p, L / \mathrm{m}^{2} \cdot h\right)$, fouling degree $(F D, \%)$ and rejection index $\left(R_{P h A C}, \%\right)$ were measured, according to the following equations:

$$
\begin{aligned}
& J p=\frac{V}{A_{m} \cdot t} \\
& F D(\%)=\left(1-\frac{J p_{f}}{J p_{0}}\right) \cdot 100 \\
& R_{P h A C}(\%)=\left(1-\frac{C_{p}}{C_{f}}\right) \cdot 100
\end{aligned}
$$

where $V$ is the volume of permeate stream $(\mathrm{L}), A_{m}$ is the effective membrane area $\left(\mathrm{m}^{2}\right), t$ is the filtration time (h), $J p_{0}$ and $J p_{f}$ are respectively the permeate fluxes at the beginning and after the filtration process with model solutions, $C_{p}$ is the concentration of each $\mathrm{PhAC}$ in the permeate stream, and $C_{f}$ is the concentration of the same $\mathrm{PhAC}$ in the feed solution.

\section{Analytical methods}

Concentrations of each PhACs in the corresponding samples (permeate and feed samples) were measured using an Agilent Technologies 1260 Infinity Ultra HighPerformance Liquid Chromatograph (UHPLC) coupled to an Agilent Technologies 6410 Triple Quadrupole Mass Spectrometer with an electrospray Turbo V ionisation source. The column was Kinetex C18 $(1.7 \mu \mathrm{m}, 100 \AA, 50$ x $2.10 \mathrm{~mm})$ from Phenomenex (France) and was maintained at a constant flow rate of $0.2 \mathrm{~mL} / \mathrm{min}$ and $30{ }^{\circ} \mathrm{C}$. PhACs were determined in both positive and negative ionisation modes, depending on the PhAC measured. Quantified and qualified transitions were optimised for each PhACs by selected reaction monitoring (SRM) and were previously described $[10,19,20]$. 


\section{Method validation}

Seven-point calibration curves were obtained using standard solutions and matrix matched calibrations with concentrations from the limit of quantification (LOQ) to 30 $\mu \mathrm{g} / \mathrm{L}$. Such solutions were injected in triplicate and the linearity was analysed by means of the linear correlation coefficient $\left(R^{2}\right)$, which was higher than 0.95 for all the PhACs tested. The limit of detection (LOD) and LOQ were calculated as the amount of analyte added to the water sample that produced in the chromatogram a peak signal of 3 and 10 times the background noise, respectively [19,21]. Method LODs are displayed in Table 3.

Table 3. Limits of detection values (LOD) and limits of the quantification (LOQ) obtained for all the

\begin{tabular}{ccc}
\multicolumn{3}{c}{ compounds tested. } \\
\hline Compound & LOD $(\mathrm{ng} / \mathrm{L})$ & LOQ $(\mathrm{ng} / \mathrm{L})$ \\
\hline Acetaminophen & 0.9 & 2.7 \\
Caffeine & 0.4 & 1.8 \\
Erythromycin & 5.0 & 20.0 \\
Ibuprofen & 5.0 & 14.4 \\
Naproxen & 0.5 & 2.0 \\
Sulfamethoxazole & 0.9 & 2.7 \\
Trimethoprim & 0.9 & 2.7 \\
\hline
\end{tabular}

\section{RESULTS AND DISCUSSION}

\section{UF experiments}

\section{Effect of $\mathrm{pH}$ on PhAC removal for UF membranes}

The $\mathrm{pH}$ of the feed solution plays a key role in the rejection of target PhACs. In order to study the effect of $\mathrm{pH}$ conditions on both the performance and removal of PhACs, rejection UF experiments were conducted at three $\mathrm{pH}$ levels (4, 7, and 10), depending on the characteristic pKa values of each PhAC, which are displayed in Table 1. 
Figure 2 shows the effect of changing feed $\mathrm{pH}$ on the rejection of PhACs for different ceramic UF membranes. The nominal concentration of each PhAC in feed stream for each $\mathrm{pH}$ was $500 \mu \mathrm{g} / \mathrm{L}$. Results indicated low rejection values for all PhACs tested, except for UF1 membrane, which has a MWCO value close to NF range. As expected, it can be observed that the removal of target PhACs was higher with membranes with lower MWCO. Generally, the separation mechanism identified for removing solutes with molecular weights larger than the MWCO of the membrane is purely size exclusion. However, ceramic UF membranes have larger MWCOs than the molecular weight of the target PhACs which indicates that size exclusion is not the main separation mechanism and therefore, the electrostatic interactions between the charge of both membrane surface and PhACs play an active role in rejection of charged solutes [13]. The isoelectric point of the ceramic membranes was about 6, resulting in membranes positively charged at $\mathrm{pH} 4$ and negatively charged at $\mathrm{pH} 7$ and 10 . At acidic $\mathrm{pH}$ (pH 4), all PhACs are neutral species, except TMT that is positively charged, similar to the charge of the membrane at this conditions. This results in slightly higher rejections for TMT at acidic $\mathrm{pH}$ due to electrostatic repulsion, which is more visible with membranes with smaller pores. However, the change of membrane charge from positive to negative at $\mathrm{pH}$ values in the alkaline region caused an electrostatic attraction between TMT and membrane surface which leads to a decrease in rejection and also, a slightly increase in membrane fouling. Among all the PhACs tested in UF experiments, ERY, IBU, NAP and SUL presented high rejections values for all membranes, which are higher when $\mathrm{pH}$ increases (for UF1 from 35\%, 31.9\%, 26.7\%, and 23.8\% at $\mathrm{pH} 4$ to 75.1\%, 52.9\%, 57.5\%, and 48.7\% at $\mathrm{pH} 10$, respectively). At pH 4, IBU and SUL exist as neutral species, changing both to negatively charge compounds at both pH 7 and 10 . This change in the charge of both organic solutes can cause an increase in their rejection 
values due to electrostatic repulsion with the negatively charged ceramic membrane. In this regard, Nghiem and Hawkes (2007) demonstrated that both IBU and SUL are highly soluble at basic $\mathrm{pH}$ where both compounds are negatively charged. Furthermore, IBU shows a decrease in their hydrophobic character when the $\mathrm{pH}$ conditions increase, which results in two hydrophilic compounds at basic $\mathrm{pH}$ [12]. Due to its speciation as a function of $\mathrm{pH}$, IBU rejection also varied with the $\mathrm{pH}$ conditions, showing remarkably high rejections when $\mathrm{pH}$ increased. NAP has similar characteristics to IBU (molecular weight, $\log \mathrm{K}_{\mathrm{ow}}$, and $\mathrm{pKa}$ ) and presents the same behaviour at the studied $\mathrm{pH}$ conditions. For these reasons, the behaviour of NAP can be extrapolated and considered similar as IBU. These pH-dependent behaviours of both IBU and NAP were proved by other authors using different membrane separation processes such as forward osmosis (FO) [22]. However, ERY exists as neutral species at both $\mathrm{pH} 4$ and 7, but it becomes negatively charged at $\mathrm{pH} 10$. Furthermore, this organic solute has the highest molecular weight, being more than twice the size of the other PhACs tested. Therefore, its molecular weight is close to MWCO of UF1 membrane together with its charge at the tested $\mathrm{pH}$ conditions can explain its high rejection values ( 75.1\%). Other PhACs as ACE and CAF are neutral and hydrophilic in all $\mathrm{pH}$ conditions tested. These compounds are not affected by the $\mathrm{pH}$ of the solution and present similar rejections for the same membrane, increasing when membranes with lower pore size were used. Other authors observed similar $\mathrm{pH}$-independent behaviour of ACE and other PhACs such as carbamazepine in different filtration experiments [12,23,24]. 

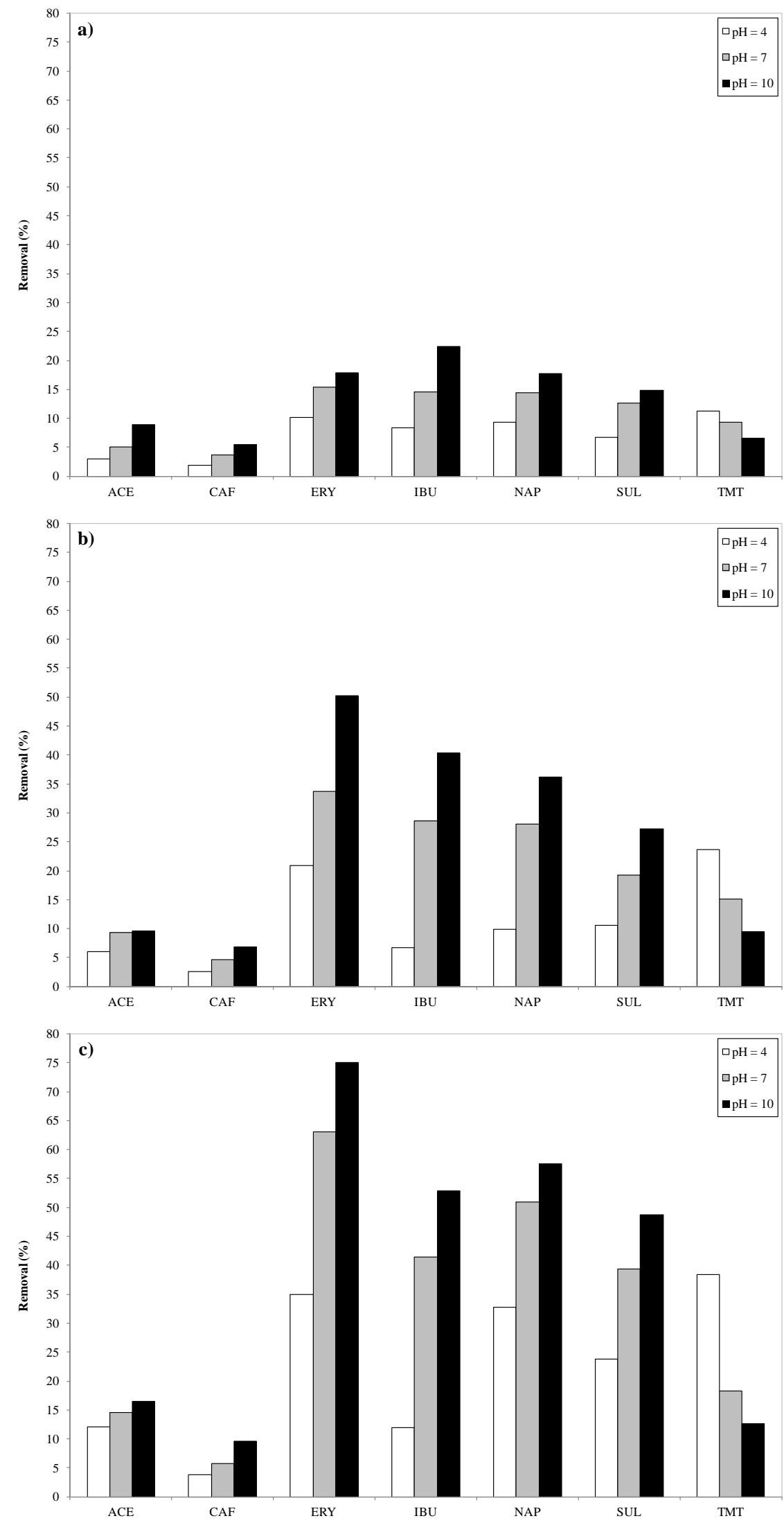

Figure 2. Rejection of PhACs by ceramic UF membranes during the membrane filtration experiments: (a) UF8 membrane, (b) UF5 membrane, and (c) UF1 membrane. Experimental conditions were: 3 bar, $300 \pm$ $10 \mathrm{~L} / \mathrm{h}$, and $25 \pm 2^{\circ} \mathrm{C}$. 


\section{Effect of MWCO of the membranes and $\mathrm{pH}$ on the membrane performance}

Table 4 represents the values of permeate flux during the fouling step and the calculated fouling degree parameter for 1, 5, and $8 \mathrm{kDa}$ membranes. Here, it can be observed the effect of the MWCO of the membrane and $\mathrm{pH}$ on the permeate flux as well as the interactions between the target PhACs and the ceramic membranes. As expected, permeate flux is higher for membranes with larger pore size at the same $\mathrm{pH}$ conditions. This can be particularly visible through the different permeate fluxes obtained for UF8 compared with those obtained for UF1. Comparing the FD results, specific flux declines observed during UF experiments are insignificant (less than $10 \%$ of the initial permeate flux) and are mainly caused by the adsorption and deposition of PhACs (in both particle and aggregate form) on the surface and/or inside the pores of the membranes. Even though the differences in percentage among them are not significant, UF1 shows the highest FD which indicates that fouling phenomena are more severe for ceramic UF membranes with lower MWCO due to the similarity between the MWCO of UF1 membrane and the molecular weight of the PhACs [25]. Due to their hydrophilic surface, the main reason for fouling in ceramic membranes cannot be the hydrophobic interactions between PhACs and membrane surface, but these membranes have a rougher surface than a typical commercial polymeric UF membrane with the same MWCO, which can cause a more severe fouling and its inherent flux decline and therefore, can favour the entrapment of PhAC molecules on the membrane [23,26,27]. 
Table 4. Results for ceramic membranes during UF experiments with a nominal PhAC concentration of $500 \mu \mathrm{g} / \mathrm{L}$. Experimental conditions were: 3 bar, $300 \pm 10 \mathrm{~L} / \mathrm{h}$, and $25 \pm 2{ }^{\circ} \mathrm{C}$.

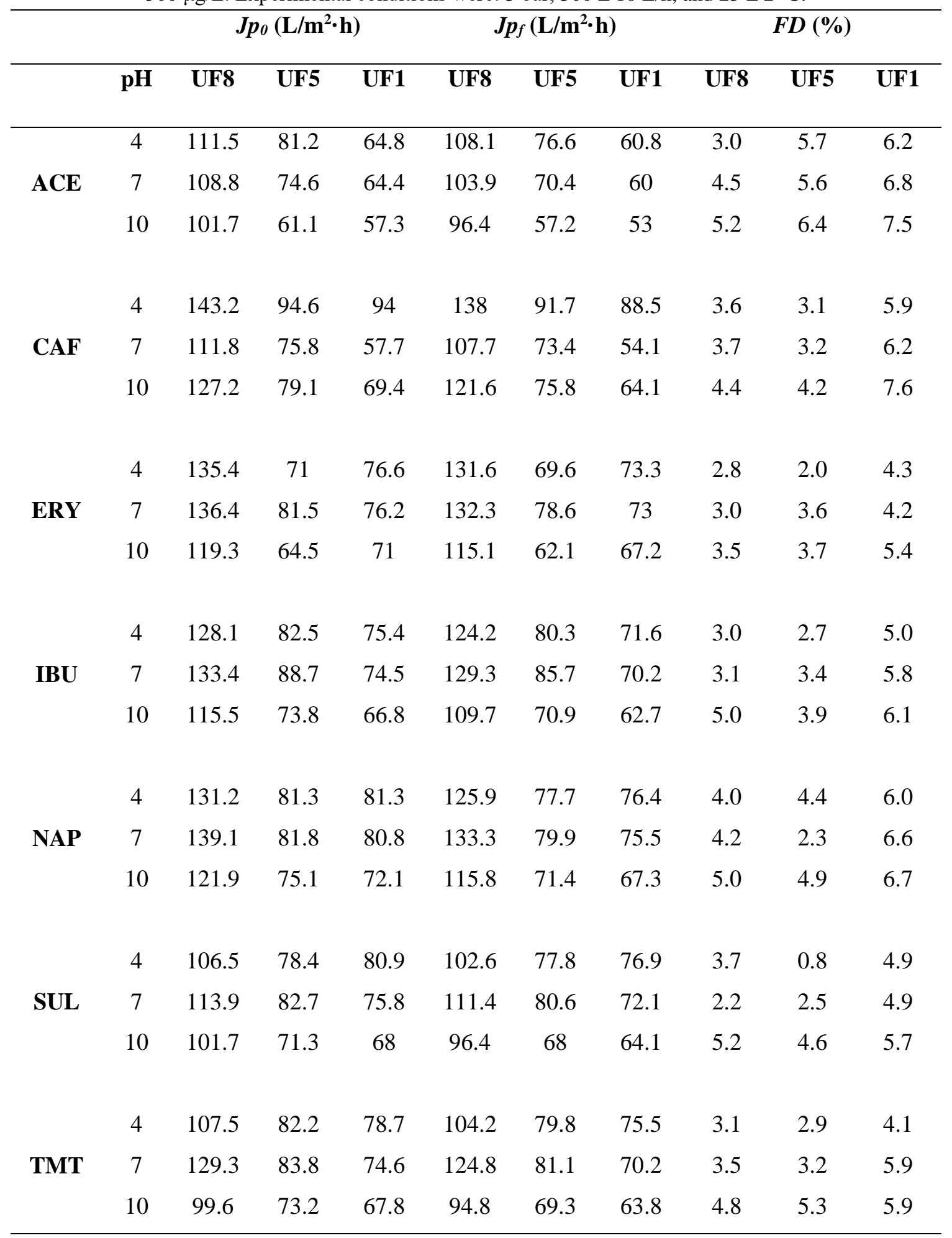

When the results of FD are compared for each $\mathrm{pH}$ tested, membrane fouling was more severe at basic conditions ( $\mathrm{pH} 10)$, where it can be also observed that the permeate flux at the beginning of the UF experiments at $\mathrm{pH} 10$ presented lower values than those UF 
experiments performed at both $\mathrm{pH} 4$ and 7. Furthermore, the rejection of the target PhACs was improved for almost all of the PhACs tested (except for TMT) due to their presence as a neutral or negatively charged species and their increase in hydrophilicity with increasing $\mathrm{pH}$, especially for SUL, NAP and IBU (see Figure 2). Those improvements can be the main cause of both fouling on the membrane (aggregations of some PhACs on the membrane surface and/or electrostatic attraction between positively/neutral charged PhACs and negatively charged surface) or inside the membrane (accumulations of aggregations of some PhACs inside the pores).

\section{NF experiments}

\section{Effect of $p H$ on PhAC removal for NF membranes}

The selected NF membrane (TFC-SR2) can be considered as a very loose NF membrane due to its MWCO ( $400 \mathrm{Da} ; 1.28 \mathrm{~nm}$ of average diameter), which is comparatively larger than the different molecular weights of the target PhACs, except of ERY with a molecular weight slightly higher than 700 Da (see Tables 1 and 2). The presence of carboxylic and amine functional groups in its structure makes TFC-SR2 susceptible to be ionised depending on the $\mathrm{pH}$ of the aqueous solution. In particular, this membrane has an isoelectric point between $\mathrm{pH} 2$ and 4, and therefore, TFC-SR2 is negatively charged at the $\mathrm{pH}$ conditions used in this study. In the same way, the semi-hydrophilic character of TFC-SR2 was reported by different researchers, presenting a water contact angle value around $61^{\circ}$, which was higher than other commercial NF membranes such as NF90 or NF270 [15,28]. The rejection of the target PhACs by the TFC-SR2 membrane during NF experiments is shown in Figure 3. It can be observed that the rejection was pH-dependent, where TFC-SR2 membrane achieved high rejection of SUL, NAP, IBU, and ERY, especially at $\mathrm{pH}$ 8. The high rejections obtained for ERY at 
all the tested $\mathrm{pH}$ conditions are mainly caused by size exclusion, due to its higher molecular weight than MWCO of the NF membrane. Despite the important role of size exclusion (molecular weight of PhACs versus MWCO of the membrane), both electrostatic and hydrophobic interactions are predominantly the main rejection mechanisms for the NF membrane used in this study, even more than for UF membranes. The rejection yields of SUL, NAP, and IBU are intimately related to the electrostatic repulsion and their log $\mathrm{K}_{\mathrm{ow}}$, where the latter indicates the hydrophilic character of a PhAC. Although SUL is hydrophilic within the $\mathrm{pH}$ range (log Kow is between 0.5 and 0.89), both NAP and IBU have a log Kow higher than 2.6, presenting high hydrophobicity which could lead to the hydrophobic interactions (adsorption) of these compounds onto the polymeric surface of the membrane [29]. Even though the adsorption on the membrane could be significant, hydrophobic PhACs are ultimately rejected due to size exclusion mechanism [13]. Likewise, the importance of electrostatic interaction should be taken into account. For SUL and IBU, the rejections vastly increase with increasing $\mathrm{pH}$ from 6 to 8 . Both organic solutes are negatively charged at these conditions, becoming highly soluble and hydrophilic with increasing $\mathrm{pH}$ (especially at basic $\mathrm{pH}$ ) which results in an increase in their rejection values due to both electrostatic repulsion and their hydrophilic character [12,15]. Similar observations to IBU were also found in the rejection yields of NAP. For ACE and CAF, rejection values are almost similar within this $\mathrm{pH}$ range. These results are in agreement with those obtained in UF experiments in this study and those obtained by other researchers with similar membranes, where these organic solutes were almost $\mathrm{pH}$-independent [23]. For TMT, high rejection values are observed at low $\mathrm{pH}$ conditions principally due to the electrostatic interactions. At pH 6, TMT is hydrophilic (log Kow between 0.5 and 0.91 ) and exists as a positively charged species. In these cases, the rejection is predominantly 
governed by electrostatic mechanisms, where the positively charged $\mathrm{PhAC}$ is attracted by the negatively charged membrane, at which the accumulation of the organic solute as a thin layer may occur. The strong interaction between this positively charged solute and the negatively charged surface of the membrane causes the dissolution and diffusion of the solute across the membrane matrix $[13,30]$. However, this organic solute changes its charge at $\mathrm{pH} 7$ (becoming a mixture of neutral and positively charged solute) and 8 (becoming a neutral or negative charged species), which causes a slightly decrease in its rejection. Hajibabania et al. (2011) considered that TMT exists as a non-ionic hydrophilic solute at $\mathrm{pH} 7$, indicating that the high rejection ( 99\%) obtained after NF experiments were clearly dependent of the molecular weight of TMT and therefore, the major separation mechanism at these conditions is size exclusion [31].

These results are in accordance with Van der Bruggen et al. (2006), who proposed a semi-quantitative assessment of the removal efficiency of organic compounds in aqueous solutions based on different physicochemical characteristics of such compounds as well as the membrane properties and the feed conditions. Selected organic compounds were classified into different categories depending on their molecular weight (versus MWCO of the tested membrane), molecular length (versus membrane average diameter), log $K_{O W}$ (hydrophilic/hydrophobic character), pKa (compared to the feed $\mathrm{pH}$ conditions), and membrane charge. The categorisation of each target PhAC can be resumed as follows [32]:

- Categories 1, 2, and 7 are related to the uncharged hydrophobic compounds and are characterised by $\mathrm{pH}<\mathrm{pKa}, \log \mathrm{K}_{\mathrm{OW}}>2$ (both for all the categories), low molecular weight $(<M W C O)$ for categories 1 and 2, and high molecular weight (> MWCO) for category 7. Among the entire target PhACs, ERY can be 
included in category 7. The organic compounds comprised in this category present high rejections (> 60\%) principally due to the steric hindrance inside the membrane pores (size exclusion), which results in a slower solute transport (as explained above in the same section).

- Categories 3, 4, 8, and 9 are related to uncharged hydrophilic compounds, which are classified according to their hydrophilicity $\left(\log K_{O W}<2\right)$ and charge $(p H<p K a)$. In categories 3 and 4, PhACs have a lower molecular weight than the MWCO of the membranes, whereas PhACs present higher molecular weight than MWCO in categories 8 and 9. Among all the PhACs tested, ACE and CAF belong to category 3 and TRI is included in category 4 when feed $p H$ is 6 or 7 . The organic compounds present in category 3 and 4 have rejection values lower than the compounds belonging to category 7 (40-70\%). This may be caused by the hydrophilicity of these PhACs, in which the adsorption has a small influence and the pH barely affects the solute rejection. In this case, the hydrophilic molecules are hydrated to a certain extent, increasing their effective size in the aqueous solutions and thus, their rejection values. However, such increments are not enough to significantly increase their rejection values due to the huge difference between the molecular weight of both ACE and CAF and the MWCO of the membrane ( $400 \mathrm{Da})$. However, TRI is larger than those compounds, presenting higher molecular length (1.42) than the average diameter of the membrane (1.28 nm). This factor leads to obtain higher rejections than ACE and CAF.

- Categories 5, 6, and 10 are related to the charged PhACs and are characterised by $\mathrm{pH}>\mathrm{pKa}$, low molecular weight $(<\mathrm{MWCO})$ for categories 5 and 6 , and high molecular weight (> MWCO) for category 10. The difference between 
categories 5 and 6 is the membrane charge (low for category 5 and high for category 6). Among them, TRI (at pH 8), IBU, NAP, and SUL can be classified into the category 6 because the membrane charge is higher at higher pHs than its isoelectric point. Expected rejection values for all these compounds are higher than $60 \%$, mainly due to the electrostatic interactions between PhACs and the large membrane surface charge. However, for TRI at $\mathrm{pH} 8$, there are not large interactions with the membrane surface, but similar rejections to those obtained at previous conditions are achieved due to the combination of size and charge interactions.



Figure 3. Rejection of PhACs by NF membrane (TFC-SR2) during the membrane filtration experiments at 5 bar, $25^{\circ} \mathrm{C}$ and $500 \pm 20 \mathrm{~L} / \mathrm{h}$.

\section{Effect of $\mathrm{pH}$ on the performance for NF membranes}

Figure 4 shows the evolution of the permeate flux over time $(4 \mathrm{~h})$ during $\mathrm{PhACs}$ filtration experiments with TFC-SR2 membrane and besides the results of the FD parameter at each $\mathrm{pH}$ condition tested. It can be seen that the performance of TFC-SR2 is clearly influenced by the change of $\mathrm{pH}$ conditions, decreasing the permeate flux when $\mathrm{pH}$ increases and thus, TFC-SR2 membrane presents the lowest permeate flux at basic 
conditions. Although the flux declines observed have no significant differences, it can be seen that the TFC-SR2 membrane presented higher FD values at higher $p H$ conditions (from 4.4 to $7.6 \%$ ). This may be caused by the hydrophobic interactions between some PhACs and the membrane surface made by polyamide, which could be related to the log Kow values of the target PhACs. Where log Kow is higher than 2, PhACs have high lipophilicity and low hydrophilicity, resulting in higher adsorption of hydrophobic PhACs onto the membrane surface due to the formation of hydrogen bonding, Van der Waals forces or electrostatic interactions $[13,33]$. This behaviour leads to a higher permeate flux decline and also an increase in membrane rejection.

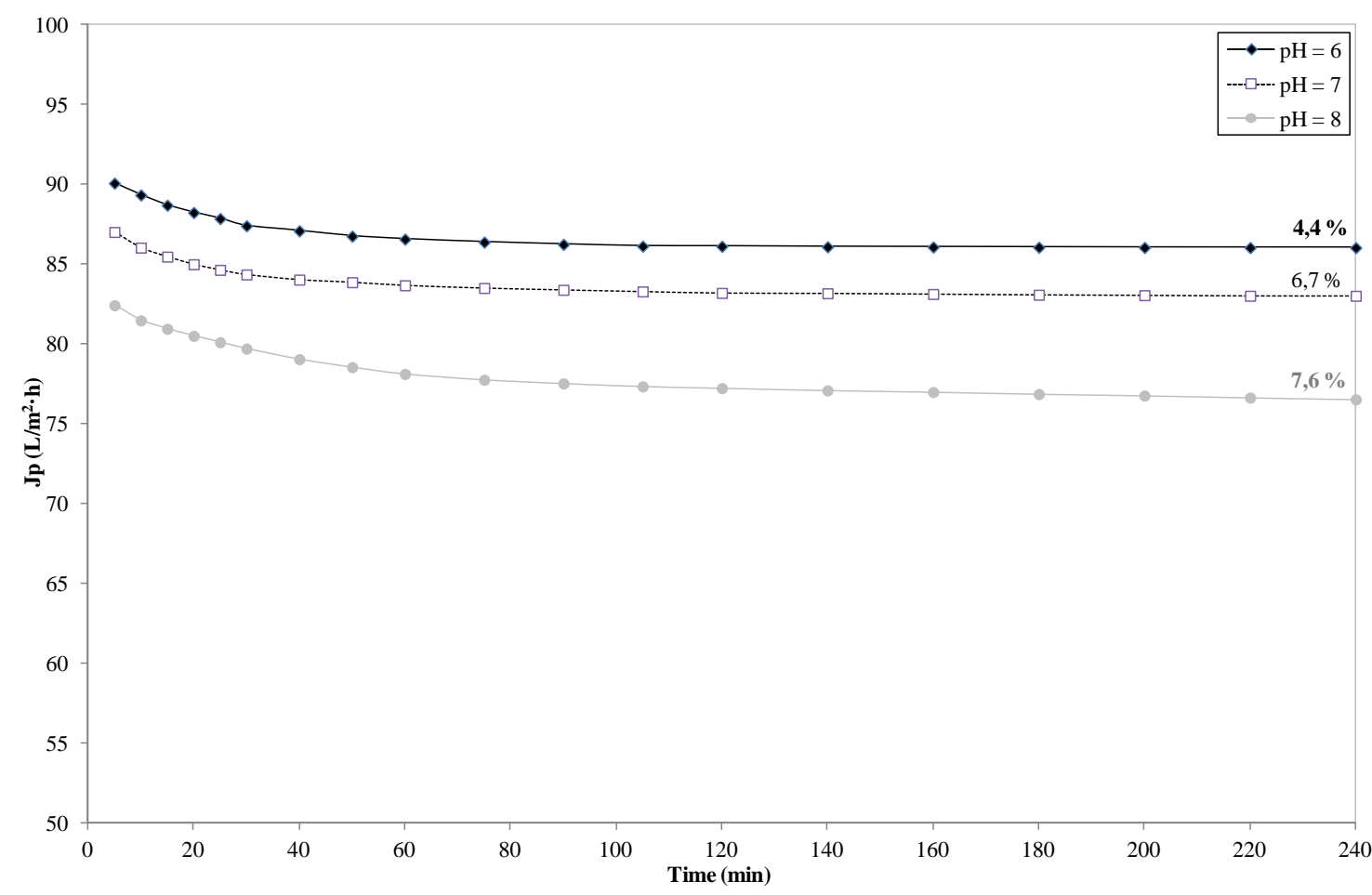

Figure 4. Evolution of the permeate flux over time (4 h) during PhACs filtration experiments with NF membrane (TFC-SR2) at 5 bar, $25^{\circ} \mathrm{C}$ and $500 \pm 20 \mathrm{~L} / \mathrm{h}$. Numerically, the results of fouling degree (FD) parameter are shown.

\section{CONCLUSIONS}

The rejection efficiencies of seven different PhACs using low-pressure membranes (within the fine ultrafiltration and loose nanofiltration range) were studied in order to 
analyse the influence of the $\mathrm{pH}$ of feed solution on their removal. Changes in $\mathrm{pH}$ conditions demonstrated the importance of physicochemical properties of the solutes (such as pKa and log Kow), which governed the separation process and also, the membrane fouling. Therefore, the results reported here indicated that the rejection was determined to be strongly $\mathrm{pH}$ dependent, especially for aqueous solutions with erythromycin, ibuprofen, naproxen, and sulfamethoxazole. These negatively charged solutes were effectively rejected at basic conditions, improving both their hydrophilicity and solubility with increasing $\mathrm{pH}$ (especially from their characteristic pKa value to basic conditions). Furthermore, high soluble and hydrophilic PhACs with high pKa values (acetaminophen and caffeine) showed low rejection values and a $\mathrm{pH}$-independent behaviour during low-pressure filtration experiments. Over all the ceramic UF membranes, multichannel $\mathrm{TiO}_{2}$ membrane with a nominal MWCO of 1,000 Da also showed the highest rejection values as well as the highest fouling degree, but the latter parameter was always lower than $10 \%$. Therefore, it can be concluded that the use of low-pressure membranes could be considered as an appropriate and sustainable supplemental technique to remove PhACs in a wastewater treatment plant.

\section{ACKNOWLEDGEMENTS}

The authors of this work wish to gratefully acknowledge the financial support from the Spanish Ministry of Economy and Competitiveness through the project CTM201342342-P.

\section{REFERENCES}

[1] F.R. Rijsberman, Water scarcity: Fact or fiction?, Agric. Water Manage., 80 (2006) 5-22. 
[2] K. Chon, J. Cho, H.K. Shon, A pilot-scale hybrid municipal wastewater reclamation system using combined coagulation and disk filtration, ultrafiltration, and reverse osmosis: Removal of nutrients and micropollutants, and characterization of membrane foulants, Bioresour. Technol., 141 (2013) 109-116.

[3] Y. Picó, D. Barceló, Transformation products of emerging contaminants in the environment and high-resolution mass spectrometry: a new horizon, Anal. Bioanal. Chem., 407 (2015) 6257-6273.

[4] X.M. Wang, B. Li, T. Zhang, X.Y. Li, Performance of nanofiltration membrane in rejecting trace organic compounds: Experiment and model prediction, Desalination, 370 (2015) 7-16.

[5] B. Silva, F. Costa, I.C. Neves, T. Tavares, Psychiatric pharmaceuticals as emerging contaminants in wastewater, Springer International Publishing, Switzerland, 2015.

[6] K.K. Ng, A.Y.C. Lin, T.H. Yu, C.F. Lin, Tertiary treatment of pharmaceuticals and personal care products by pretreatment and membrane processes, Sustainable Environ. Res., 21 (3) (2011) 173-180.

[7] K. Fischer, M. Grimm, J. Meyers, C. Dietrich, R. Gläser, A. Schulze, Photoactive microfiltration membranes via directed synthesis of $\mathrm{TiO}_{2}$ nanoparticles on the polymer surface for removal of drugs from water, J. Membr. Sci., 478 (2015) 49-57.

[8] K. Kimura, G. Amy, J.E. Drewes, T. Heberer, T. Kim, Y. Watanabe, Rejection of organic micropollutants (disinfection by-products, endocrine disrupting compounds, and pharmaceutically active compounds) by NF/RO membranes, J. Membr. Sci., 227 (2003) 113-121.

[9] S.A. Snyder, S. Adham, A.M. Redding, F.S. Cannon, J. DecCarolis, J. Oppeneimer, E.C. Wert, Y. Yoon, Role of membranes and activated carbon in the removal of endocrine disruptors and pharmaceuticals, Desalination, 202 (2007) 156-181. 
[10] P. Vazquez-Roig, V. Andreu, M. Onghena, C. Blasco, Y. Picó, Assessment of the occurrence and distribution of pharmaceuticals in a Mediterranean wetland (L'Albufera, Valencia, Spain) by LC-MS/MS, Anal. Bioanal. Chem., 400 (2011) 1287-1301.

[11] E. Gracia-Lor, J.V. Sancho, R. Serrano, F. Hernández, Occurrence and removal of pharmaceuticals in wastewater treatment plants at the Spanish Mediterranean area of Valencia, Chemosphere, 87 (2012) 453-462.

[12] L.D. Nghiem, S. Hawkes, Effects of membrane fouling on the nanofiltration of pharmaceutically active compounds (PhACs): Mechanisms and role of membrane pore size, Sep. Purif. Technol., 57 (2007) 182-190.

[13] S.O. Ganiyu, E.D. Van Hullebusch, M. Cretin, G. Esposito, M.A. Oturan, Coupling of membrane filtration and advanced oxidation processes for removal of pharmaceutical residues: a critical review, Sep. Purif. Technol., 156 (2015) 891-914.

[14] C. Labbez, P. Fievet, F. Thomas, A. Szymczyk, A. Vidonne, A. Foissy, P. Pagetti, Evaluation of the "DSPM" model on a titania membrane: measurements of charged and uncharged solute retention, electrokinetic charge, pore size, and water permeability, J. Colloid Interf. Sci., 262 (2003) 200-211.

[15] A. Simon, L.D. Nghiem, P. Le-Clech, S.J. Khan, J.E. Drewes, Effects of membrane degradation on the removal of pharmaceutically active compounds (PhACs) by NF/RO filtration processes, J. Membr. Sci., 340 (2009) 16-25.

[16] J. Kujawa, W. Kujawski, Functionalization of ceramic metal oxide powders and ceramic membranes by perfluoroalkylsilanes and alkylsilanes possessing different reactive groups: physicochemical and tribological properties, ACS Appl. Mater. Interfaces, 8 (2016) 7509-7521.

[17] J. Kujawa, S. Cerneaux, W. Kujawski, M. Bryjak, J. Kujawski, How to functionalize ceramics by perfluoroalkylsilanes for membrane separation process? 
Properties and application of hydrophobized ceramic membranes, ACS Appl. Mater. Interfaces, 8 (2016) 7564-7577.

[18] J. Garcia-Ivars, M.I. Iborra-Clar, M.I. Alcaina-Miranda, J.A. Mendoza-Roca, L. Pastor-Alcañiz, Surface photomodification of flat-sheet PES membranes with improved antifouling properties by varying UV irradiation time and additive solution $\mathrm{pH}$, Chem. Eng. J., 283 (2016) 231-242.

[19] A. Vona, F. Di Martino, J. García-Ivars, Y. Picó, J.A. Mendoza-Roca, M.I. IborraClar, Comparison of different removal techniques for selected pharmaceuticals, J. Water Process Eng., 5 (2015) 48-57.

[20] M.J. Andrés-Costa, U. Escrivá, V. Andreu, Y. Picó, Estimation of alcohol consumption during "Fallas” festivity in the wastewater of Valencia city (Spain) using ethyl sulphate as a biomarker, Sci. Total Environ., 541 (2016) 616-622.

[21] E. Carmona, V. Andreu, Y. Picó, Occurrence of acidic pharmaceuticals and personal care products in Túria River Basin: from waste to drinking water, Sci. Total Environ., 484 (2014) 53-63.

[22] X. Jin, J. Shan, C. Wang, J. Wei, C.Y. Tang, Rejection of pharmaceuticals by forward osmosis membranes, J. Hazardous Mater., 227-228 (2012) 55-61.

[23] E.E. Chang, Y.C. Chang, C.H. Liang, C.P. Huang, P.C. Chiang, Identifying the rejection mechanism for nanofiltration membranes fouled by humic acid and calcium ions exemplified by acetaminophen, sulfamethoxazole and triclosan, J. Hazardous Mater., 221-222 (2012) 19-27.

[24] M. Xie, W.E. Price, L.D. Nghiem, Rejection of pharmaceutically active compounds by forward osmosis: role of solution $\mathrm{pH}$ and membrane orientation, Sep. Purif. Technol., 93 (2012) 107-114. 
[25] M.J. Corbatón-Báguena, S. Álvarez-Blanco, M.C. Vincent-Vela, Cleaning of ultrafiltration membranes fouled with BSA by means of saline solutions, Sep. Purif. Technol., 125 (2014) 1-10.

[26] P.J. Evans, M.R. Bird, A. Pihlajamäki, M. Nyström, The influence of hydrophobicity, roughness and charge upon ultrafiltration membranes for black tea liquor clarification, J. Membr. Sci., 313 (2008) 250-262.

[27] M.J. Corbatón-Báguena, S. Álvarez-Blanco, M.C. Vincent-Vela, Salt cleaning of ultrafiltration membranes fouled by whey model solutions, Sep. Purif. Technol., 132 (2014) 226-233.

[28] D. Norberg, S. Hong, J. Taylor, Y. Zhao, Surface characterization and performance evaluation of commercial fouling resistant low-pressure RO membranes, Desalination, 202 (2007) 45-52.

[29] Y. Yoon, P. Westerhoff, S.A. Snyder, E.C. Wert, Nanofiltration and ultrafiltration of endocrine disrupting compounds, pharmaceuticals and personal care products, J. Membr. Sci., 270 (2006) 88-100.

[30] A.R.D. Verliefde, S.G.J. Heijman, E.R. Cornelissen, G. Amy, B. Van der Bruggen, J.C. Van Dijk, Influence of electrostatic interactions on the rejection with NF and assessment of the removal efficiency during NF/GAC treatment of pharmaceutically active compounds in surface water, Water Res., 41 (2007) 3227-3240.

[31] S. Hajibabania, A. Verliefde, J.E. Drewes, L.D. Nghiem, J. McDonald, S. Khan, P. Le-Clech, Effect of fouling on removal of trace organic compounds by nanofiltration, Drinking Water Eng. Sci., 4 (2011) 71-82.

[32] B. Van der Bruggen, A. Verliefde, L. Braeken, E.R. Cornelissen, K. Moons, J. Verbeck, H. Van Dijk, G. Amy, Assessment of a semi-quantitative method for estimation 
of the rejection of organic compounds in aqueous solution in nanofiltration, J. Chem.

Technol. Biotechnol., 81 (2006) 1166-1176.

[33] López Fernández, R., McDonald, J.A., Khan, S.J., Le-Clech, P., Removal of pharmaceuticals and endocrine disrupting chemicals by a submerged membrane photocatalysis reactor (MPR), Separation and Purification Technology 127 (2014) 131139.

\section{LIST OF SYMBOLS}

\section{Variables}

$A_{m}$

Effective area of the membrane $\left(\mathrm{m}^{2}\right)$

$C_{f} \quad$ Concentration of each pharmaceutically active compound in the feed stream $(\mu \mathrm{g} / \mathrm{L}$ and $\mathrm{ng} / \mathrm{L})$

$C_{p} \quad$ Concentration of each pharmaceutically active compound in the permeate stream $(\mu \mathrm{g} / \mathrm{L}$ and $\mathrm{ng} / \mathrm{L})$

FD $\quad$ Fouling degree (\%)

$J_{p} \quad$ Permeate flux $\left(\mathrm{L} / \mathrm{m}^{2} \cdot \mathrm{h}\right)$

$J_{p 0} \quad$ Permeate flux at the beginning of filtration experiments $\left(\mathrm{L} / \mathrm{m}^{2} \cdot \mathrm{h}\right)$

$J_{p f} \quad$ Permeate flux at the end of filtration experiments $\left(\mathrm{L} / \mathrm{m}^{2} \cdot \mathrm{h}\right)$

$\log K_{O W} \quad$ Logarithm of the octanol-water partition coefficient (dimensionless)

MWCO Molecular weight cut-off (Da)

pKa Dissociation constant (dimensionless)

$R_{P h A C s} \quad$ Rejection index of pharmaceutically active compounds (\%)

$t$

Filtration time (h)

$T$

Temperature $\left({ }^{\circ} \mathrm{C}\right)$

V

Total volume permeated during an experimental time interval (L) 
$\Delta P \quad$ Transmembrane pressure (bar)

\section{Abbreviations}

ACE Acetaminophen

APIs Active pharmaceutical ingredients

CAF Caffeine

ERY Erythromycin

FO Forward osmosis

HPLC High-Performance Liquid Chromatography

IBU Ibuprofen

NAP Naproxen

NF Nanofiltration

NOM Natural organic matter

PhACs Pharmaceutically active compounds

RO Reverse osmosis

SRM Selected reaction monitoring

SUL Sulfamethoxazole

TMT Trimethoprim

UF Ultrafiltration 